\title{
Recurrence of intravenous talc granulomatosis following single lung transplantation
}

\author{
Richard C Cook $M D^{1}$, Guy Fradet $M D^{1}$, John $C$ English $\mathrm{MD}^{2}$, John Soos $\mathrm{PhD}^{3}$, \\ Nestor L Müller MD ${ }^{4}$, Thomas P Connolly MD, Robert D Levy MD FCCP ${ }^{1}$ \\ ${ }^{1}$ University of British Columbia Lung Transplant Program, ${ }^{2}$ Department of Pathology, \\ ${ }^{3}$ Department of Psychology and ${ }^{4}$ Department of Radiology, Vancouver Hospital and Health \\ Sciences Centre, Vancouver, British Columbia
}

RC Cook, G Fradet, JC English, J Soos, NL Müller, TP Connolly, RD Levy. Recurrence of intravenous talc granulomatosis following single lung transplantation. Can Respir J 1998;5(6):511-514.

Advanced pulmonary disease is an unusual consequence of the intravenous injection of oral medications, usually developing over a period of several years. A number of patients with this condition have undergone lung transplantation for respiratory failure. However, a history of drug abuse is often considered to be a contraindication to transplantation in the context of limited donor resources. A patient with pulmonary talc granulomatosis secondary to intravenous methylphenidate injection who underwent successful lung transplantation and subsequently presented with recurrence of the underlying disease in the transplanted lung 18 months after transplantation is reported.

Key Words: Intravenous drug abuse, Lung transplantation, Talc granulomatosis

$\mathrm{I}$ ntravenous injection of oral medications is an unusual cause of progressive pulmonary dysfunction (1). A 48-year-old woman with a remote history of intravenous methylphenidate (Ritalin, Novartis) abuse underwent single lung transplantation for advanced respiratory failure. Eighteen months after transplantation, she was evaluated for a new
Récidive d'une granulomatose au talc par injection intraveineuse après une transplantation unipulmonaire

RÉSUMÉ : Une maladie pulmonaire à un stade avancé résulte parfois de l'injection intraveineuse de médicaments prévus pour une administration orale, et qui évolue généralement sur une période de plusieurs années. Un certain nombre de patients accusant cette affection ont subi une transplantation pulmonaire pour insuffisance respiratoire. Cependant, des antécédents d'abus de drogues sont souvent considérés comme une contre-indication à la transplantation dans le contexte d'un bassin limité de donneurs. Le cas d'un patient atteint d'une granulomatose pulmonaire au talc secondaire à l'injection intraveineuse de méthylphénidate et qui a subi une transplantation pulmonaire avec succès puis, une récidive de la maladie sous-jacente dans le poumon transplanté dix huit mois après la greffe est décrit. 


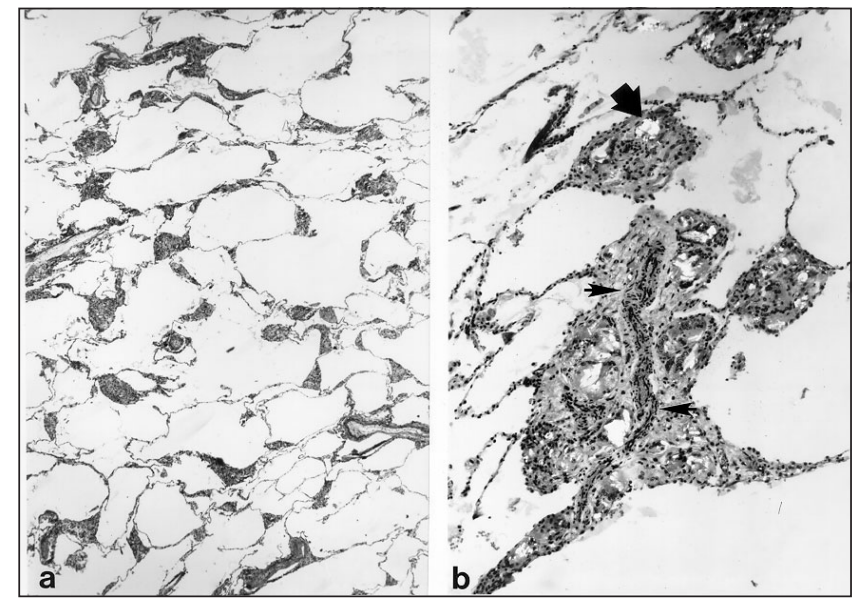

Figure 1) a Low power photomicrograph of the patient's explanted lung demonstrating numerous discrete interstitial nodules. Although the intervening alveolar walls are of relatively normal thickness, there is diffuse loss of parenchyma in a pattern of panacinar emphysema. Movat pentachrome, original magnification 25x. b Higher magnification of $\mathbf{a}$. The nodules are multinucleated histiocytic granulomas directed against foreign material in the form of birefringent plate-like crystals consistent with talc (large arrow). Note that the granulomas are mostly extravascular (small arrows denote small pulmonary artery). Movat pentachrome, original magnification $100 x$, polarized illumination

ratory failure resulting from talc granulomatosis. Furthermore, this case provides a cautionary note regarding the wisdom of performing transplantation in patients with a significant history of substance abuse.

\section{CASE PRESENTATION}

A 48-year-old woman was referred to the University of British Columbia Lung Transplant Program with respiratory failure in July 1995. She had a 40-pack-year history of smoking and a 20 -year history of intravenous drug abuse beginning in her 20s, with five to six years of heroin addiction. She was enrolled in a methadone detoxification program in the late 1970s but soon thereafter became addicted to intravenous methylphenidate (Ritalin). Between 1980 and 1988, she injected three to four tablets of methylphenidate at least twice daily (calculated intravenous exposure more than 20,000 tablets in total).

Beginning in 1983, the patient noted progressive dyspnea. In 1988, she had an episode of respiratory failure related to septic pulmonary emboli and required intubation. At that time, she stopped smoking and all intravenous drug use. Despite this, her pulmonary function status worsened to the point where she became oxygen-dependent. Computed tomography (CT) scan of the chest demonstrated severe diffuse bilateral panacinar emphysema. She was, therefore, assessed for lung transplantation, including careful evaluation by a transplant psychologist, and an alcohol and chemical dependency specialty team regarding risk of recurrent intravenous drug abuse. In view of her seven-year history of abstinence from any substance abuse, it was felt that she had an extremely low risk for recurrent intravenous drug use, and she was, therefore, listed for single lung transplantation.

The patient underwent an uncomplicated right single lung transplantation in September 1995. At the time of transplantation, the patient had physiological evidence of severe airflow obstruction, with forced expiratory volume in $1 \mathrm{~s}$ $\left(\mathrm{FEV}_{1}\right) 0.54 \mathrm{~L}$ ( $21 \%$ predicted), forced vital capacity (FVC) $1.54 \mathrm{~L}$ (45\% predicted), residual volume $5.24 \mathrm{~L}$ (294\% predicted) and total lung capacity $6.67 \mathrm{~L}$ (128\% predicted). Carbon monoxide diffusing capacity of the lungs was $41 \%$ of predicted. Alpha-1 antitrypsin levels were in the normal range. Gross pathology of the explanted native lung showed evidence of panacinar emphysema. Histological studies demonstrated numerous talc granulomas, which consisted of diffuse stellate expansions of the interstitium formed by multinucleated histiocytic giant cells (Figure 1). Within these granulomas, extensive deposits of refractile foreign material were identified, which demonstrated the characteristic plate-like birefringence of talc. The granulomas were virtually all extra- or perivascular in location. The patient received an immunosuppression regimen consisting of cyclosporine, azathioprine and prednisone. Routine surveillance transbronchial biopsies were obtained three, six, nine, 12 and 18 months post-transplantation. Until April 1997, all biopsies were free of abnormalities, and the patient did not experience any major infections. Pulmonary function improved markedly, with $\mathrm{FEV}_{1}$ and $\mathrm{FVC}$ reaching peak values of $1.54 \mathrm{~L}$ (55\% predicted) and $2.36 \mathrm{~L}$ (69\% predicted), respectively, six months post-transplantation. She returned to work parttime five months after transplantation.

In April 1997, the patient was seen by her treating physician because of a four-week history of dry cough, dyspnea and rhinorrhea, which had not improved with oral antibiotics. The physical examination was normal except for a new finding of diminished breath sounds and wheezing over the transplanted lung. $\mathrm{FEV}_{1}$ was $0.86 \mathrm{~L}$. A chest radiograph was unchanged from the stable post-transplantation appearance. She was started on azithromycin and oral prednisone $(1 \mathrm{mg} / \mathrm{kg} /$ day orally) after consultation with her transplant respirologist.

The patient was seen in the lung transplant clinic three days later, by which time her symptoms had improved. Pulmonary function studies demonstrated FEV 1 1.43 L (51\% predicted), similar to stable post-transplantation baseline values. A high resolution CT scan of the chest demonstrated severe panacinar emphysema in the native left lung (Figure 2 ). The appearance of the transplanted right lung was unremarkable and was unchanged from that seen on the CT scan that was performed one month post-transplantation.

The patient underwent fibre optic bronchoscopy, at which time bronchoalveolar lavage and transbronchial biopsy specimens were obtained from the transplanted right lung. Cultures were negative for bacterial, viral and fungal infection. Transbronchial biopsies revealed minimal acute rejection (International Society for Heart and Lung Transplantation grade A1). The specimens also revealed numerous small birefringent particles lying within the alveolar capillary lu- 


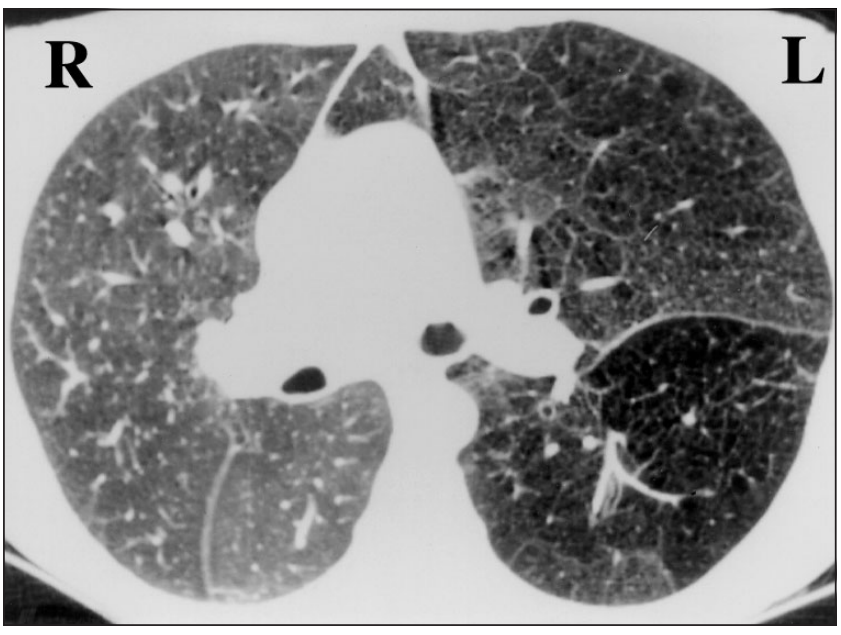

Figure 2) High resolution computed tomography (CT) scan using $1 \mathrm{~mm}$ collimation demonstrates severe panacinar emphysema in the native lung. Note increased volume of the left lung $(L)$ with associated herniation to the right lung $(R)$. No nodules are identified in the native left lung or in the transplanted right lung. The appearance of the transplanted right lung had not changed on the CT compared with a study performed 1 month following transplantation

mens or attended by a poorly formed (early) histiocytic response, much different in size from those in the explanted lung (Figure 3). Subsequently, the patient admitted to recurrent intravenous drug abuse.

\section{DISCUSSION}

Only four diseases - sarcoidosis, lymphangioleiomyomatosis, giant cell interstitial pneumonitis and diffuse panbronchiolitis - have been reported to recur in the lung allograft (2). This is the first report of recurrence of talc granulomatosis due to relapse of drug abuse. The finding of talc granulomas in this patient's transplanted lung was unexpected, with none of the previous transbronchial biopsies showing talc granulomas. The patient presented with documented lung pathology after a relatively small exposure to the intravenous talc compared with that of previously reported cases of talc granulomatosis in nontransplant patients.

Pulmonary disease has been well described in individuals who have chronically engaged in the intravenous injection of drugs intended for oral use (1). The pills are crushed, mixed in water, heated and subsequently drawn into a syringe to be injected intravenously. Many drugs have been abused in this fashion, including amphetamines (1), methylphenidate hydrochloride (1) and a variety of narcotic preparations, especially methadone hydrochloride (3). These oral medications are bound to an insoluble filler (eg, talc in methylphenidate), which is important both as a binding agent as well as to prevent the tablet from sticking to the manufacturing equipment (1).

When injected intravenously, talc particles become lodged in pulmonary (and systemic) arterioles and capillaries, resulting in thrombosis, vascular and perivascular fibrosis, and chronic inflammation (1). Eventually the particles migrate to the pulmonary interstitium where they provoke a

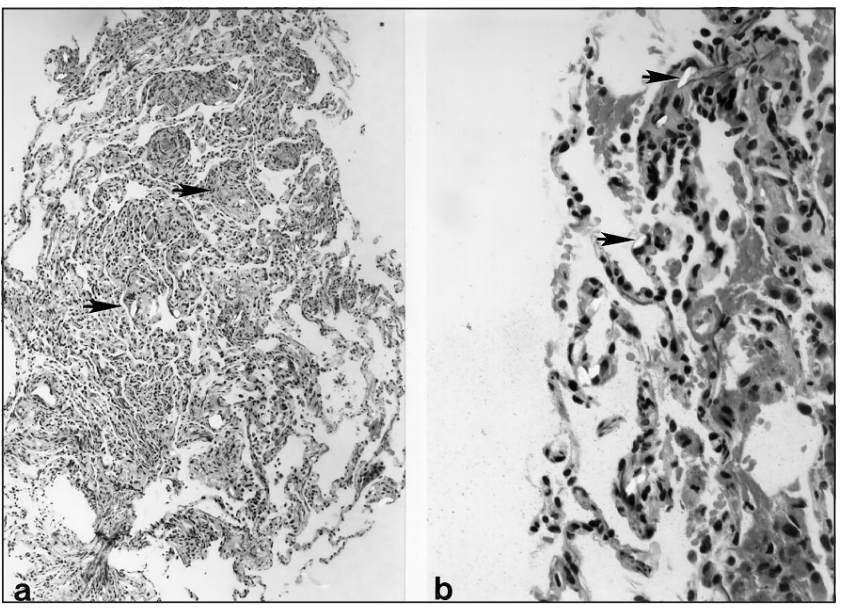

Figure 3) a Low power photomicrograph of surveillance transbronchial biopsy containing small, ill-defined granulomas (arrows). Movat pentachrome, original magnification 25x, polarized illumination. $\mathbf{b}$ Higher magnification of $\mathbf{a}$. Arrows indicate talc particles. Note that most have not yet become associated with a granulomatous response. Many particles are identified within the alveolar capillaries, suggesting very recent exposure. Movat pentachrome, original magnification 250x, polarized illumination

foreign body giant cell reaction. These lesions have been reported to result in pulmonary hypertension (4) and interstitial pulmonary fibrosis (1). They can also be associated, as in our patient, with physiological changes characteristic of emphysema, including chronic airflow limitation, gas trapping and hyperinflation, and decreased diffusing capacity (3).

The patient's clinical signs, symptoms and spirometry improved rapidly with azithromycin and corticosteroids within several days, with $\mathrm{FEV}_{1}$ returning to the stable posttransplantation baseline level within several days. This raises the possibility that unidentified infection may have been the cause of the deterioration. Alternatively, the augmented steroids may have served a role in reducing bronchial hyperresponsiveness related to an acute inflammatory response from the granulomatous process. This is supported by the presence of wheezing at the time of presentation as well as reversible airflow limitation on spirometry.

Although this patient's high resolution CT of the transplanted lung was unremarkable, the usual findings with talc granulomatosis consist of ground-glass opacities or fine nodularity throughout the lungs (5). The nodules measure $1 \mathrm{~mm}$ or less in diameter. In patients with more advanced disease, the nodules coalesce into larger nodules and eventually produce a pattern of conglomerate masses in the upper lobes with compensatory overinflation of the lower lobes, a pattern that is similar to that of progressive massive fibrosis in silicosis (5). In patients with intravenous methylphenidate abuse, a relatively common finding on high resolution $\mathrm{CT}$ is the presence of bilateral, primarily panacinar emphysema (6).

The transbronchial biopsies demonstrated the most significant abnormality. The short time between transplantation and biopsy demonstration of the lesions (18 months) suggests that extensive and diffuse involvement can occur with a relatively limited exposure to intravenous talc. The disposi- 
tion of fine talc particles within the alveolar capillaries in the absence of a significant host granulomatous response suggests that the implantation was relatively recent, because granulomas tend to appear more in the interstitium with greater drug exposure (7). This may be the explanation for the lack of permanent change in pulmonary function, as well as the absence of significant abnormalities in the transplant lung on the high resolution CT scan. Alternatively, the patient's immunosuppressive regimen may have retarded the typical foreign body response. It will be of interest to follow subsequent lung biopsies in this patient to document the progression of the granulomatous response to residual talc.

This case emphasizes the importance of careful pretransplantation assessment of psychosocial factors in the selection of appropriate candidates for transplantation. Ongoing substance abuse is generally considered a psychosocial contraindication to transplantation (8). Many centres, including our

\section{REFERENCES}

1. Paré JP, Coté G, Fraser RS. Long-term follow-up of drug abusers with intravenous talcosis. Am Rev Respir Dis 1989;139:233-41.

2. Trulock EP. Lung transplantation. Am J Respir Crit Care Med 1997; 155:789-818.

3. Paré JA, Fraser RG, Hogg JC, Howlett JG, Murphy SB. Pulmonary "mainline" granulomatosis: talcosis of intravenous methadone use. Medicine 1979;58:229-39.

4. Tomashefski JF Jr, Hirsch CS. The pulmonary vascular lesions of intravenous drug abuse. Hum Pathol 1980;11:133-45.

5. Padley SPG, Adler BD, Staples CA, Miller RR, Müller NL. Pulmonary talcosis: CT findings in three cases. Radiology 1993;186:125-7.

6. Stern EJ, Frank MS, Schmutz JF, Glenny RW, Schmidt RA, Godwin JD. Panlobular pulmonary emphysema caused by IV injection own, require a six-month abstinence as a minimum condition for attaining transplant candidacy status. However, recent work questions the predictive utility of this approach. For example, Gerhardt et al (9) found no correspondence between the duration of pretransplantation abstinence and subsequent recidivism in their sample of patients with alcoholic cirrhosis being referred for liver transplantation. This patient's evolution reinforces the often cited observation that substance abuse is a chronic, remitting condition (10). After a remarkable seven-year abstinence, amidst a re-emergence of psychosocial stressors, she regressed to self-destructive attempts at coping with recurrent intravenous drug use. Clearly, every case has to be considered on its own merits. However a history of substance abuse, even in the remote past, should raise substantial concerns as to the likelihood of a long term successful transplantation, especially when considering the prevailing limited donor supply.

of methylphenidate (Ritalin): findings on chest radiographs and CT scans. AJR Am J Roentgenol 1994;162:555-70.

7. Waller BF, Brownlee WJ, Roberts WC. Self-induced pulmonary granulomatosis. A consequence of intravenous injection of drugs intended for oral use. Chest 1980;78:90-4.

8. Olbrisch ME, Levenson JM. Psychosocial assessment of organ transplant candidates: current status of methodological and philosophical issues. Psychosomatics 1995;36:236-43.

9. Gerhardt TC, Goldstein RM, Urshel HC, et al. Alcohol uses following liver transplantation for alcoholic cirrhosis. Transplantation 1996;62:1060-3.

10. Thoms DL. Introduction to Addictive Behaviours. New York: The Guilford Press, 1994. 


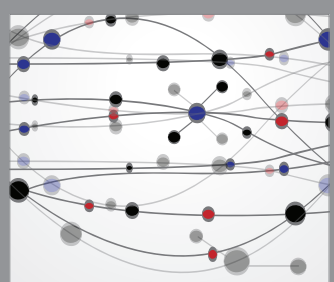

The Scientific World Journal
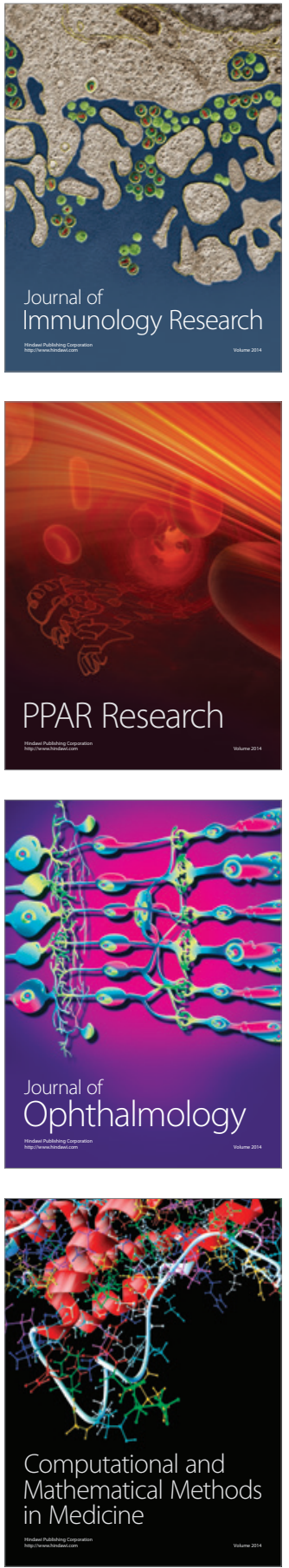

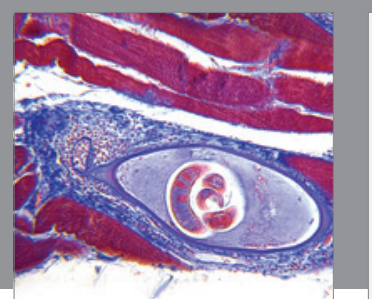

Gastroenterology Research and Practice

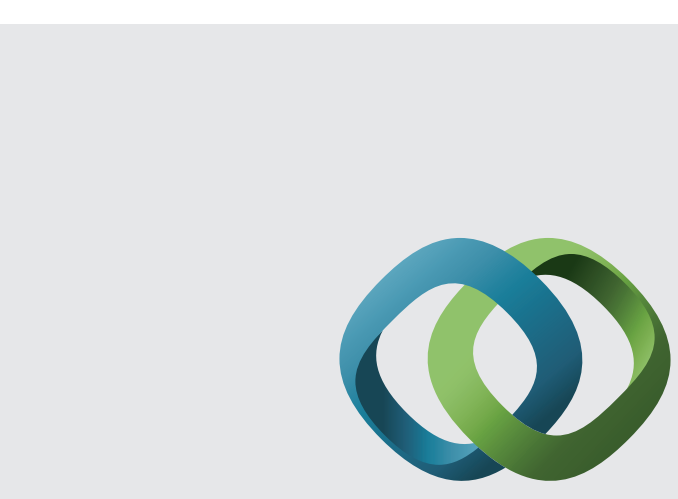

\section{Hindawi}

Submit your manuscripts at

http://www.hindawi.com
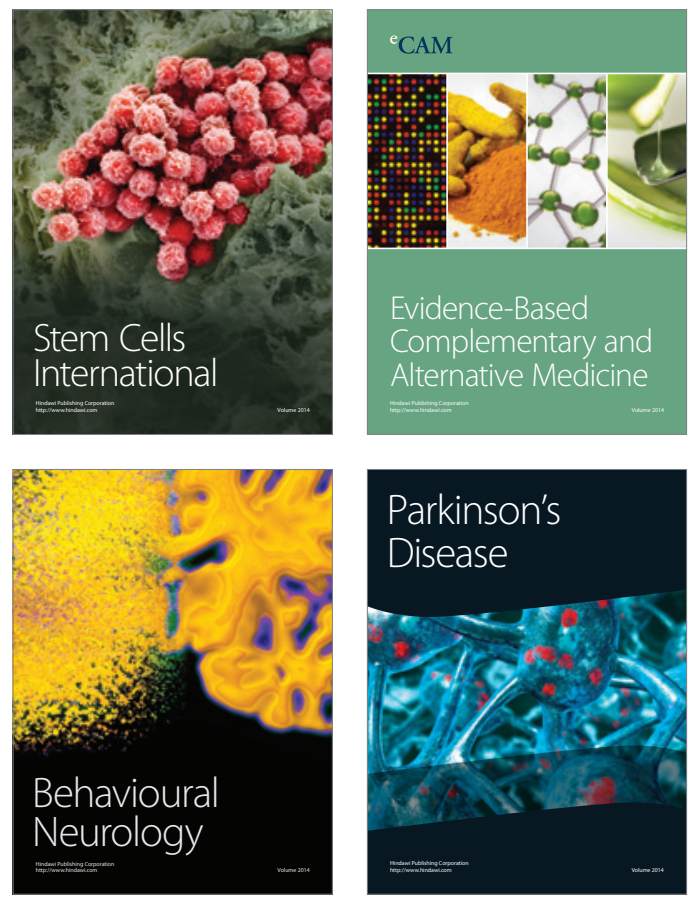
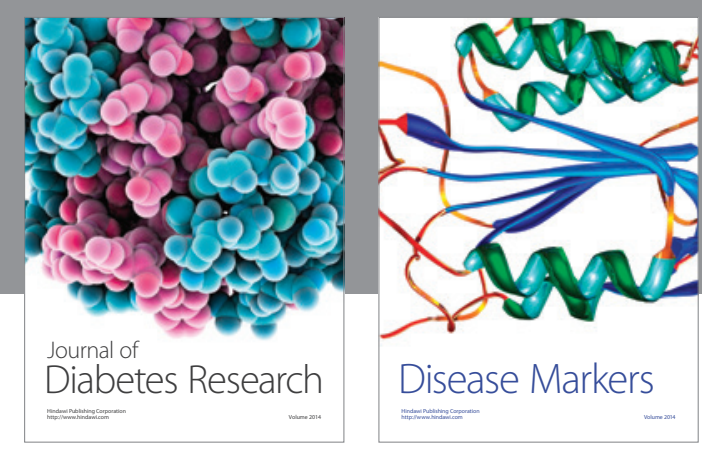

Disease Markers
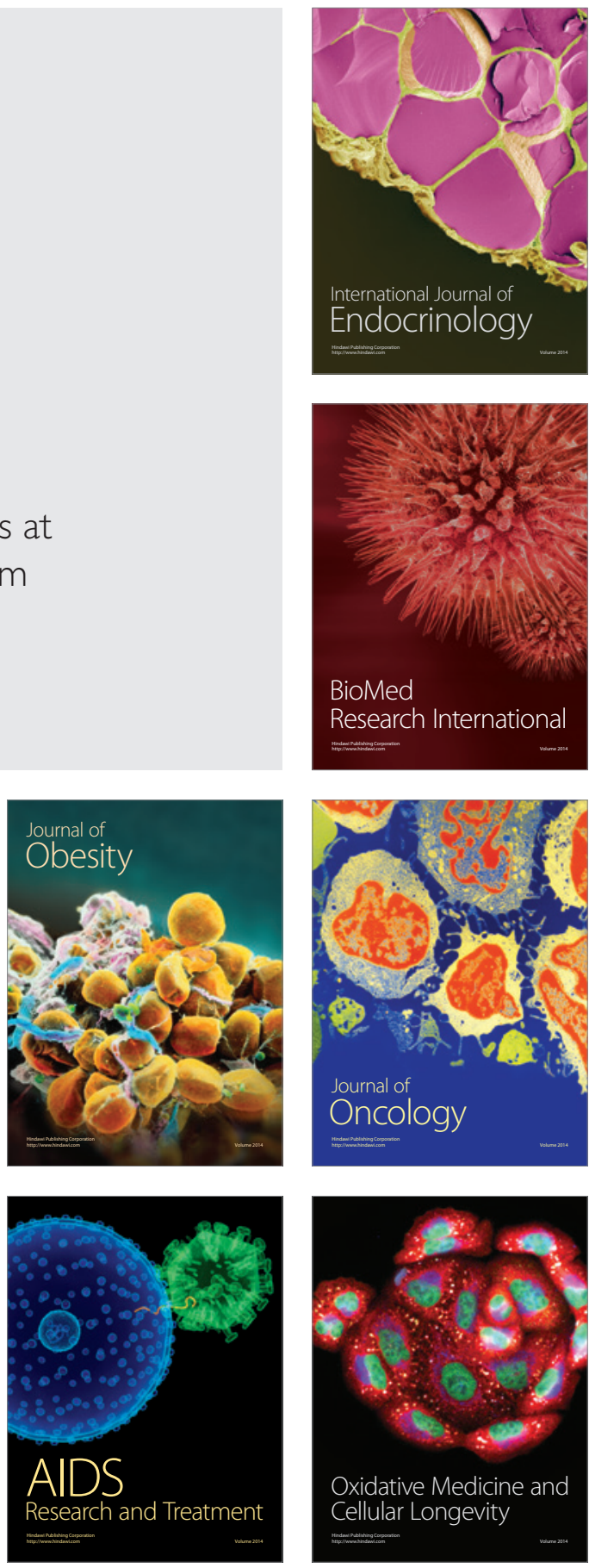